\title{
IMPLIKASI GADGET TERHADAP MASYARAKAT HINDU DI BALI
}

\author{
Oleh \\ Ni Nyoman Sri Widiasih \\ Dosen pada Fakultas Brahma Widya IHDN Denpasar
}

\begin{abstract}
Abstrack
Gadget is one of the successful communication technology products is booming in this millennium century. Gedget allows humans to interact or communicate with another human being without a limited time, place and space.

Progress society characterized by the development of science and technology. Science and technology major effect on human life and activity. Positive implications that science and technology can facilitate human in Survival. With the science and technology, human creativity challenged to continue and develop ideas berkualitasnya to be something useful for humans, and the natural surroundings. While the negative implication is that he has now increasingly rely on technology to run his life, so he became a creature lazy, spoiled and less willing to work hard. In reality, not all the problems facing humanity can be solved by technology.

The function of religion as a human guide in these conditions is very important. Hinduism is not anti to the technology, it Hindu suggest the importance of building a strong civilization. Hinduism has given life provision and guidelines long before humans evolved in advanced age as it is today. The concept of Tri Pramana and Wiweka should remain aware and understood in Survival.
\end{abstract}

\section{Keywords: Gadgets, Science, Religion Hindu}

\section{PENDAHULUAN}

Globalisasi didefenisikan sebagai semua proses yang merujuk kepada penyatuan seluruh warga dunia menjadi sebuah kelompok masyarakat global (Sunarso dkk, 2006;134). Globalisasi disebabkan kemajuan teknologi dalam bidang komunikasi, informasi serta perekembangan transportasi. Kemajuan masyarakat yang ditandai dengan berkembangnya ilmu dan teknologi membuat umat manusia semakin mudah melangsungkan kehidupan. Contohnya, dengan ditemukannya transportasi, orang dapat dengan mudah berpindah dari satu tempat ke tempat lainnya. Setelah ditemukannya media televisi, orang dapat melihat kejadian di belahan dunia lain dalam hitungan detik. Kecanggihan internet dan telepon seluler/ handphone, memungkikan orang dapat berkomunikasi tanpa batas waktu, tempat dan ruang.

Disisi lain ada beberapa hal yang nampaknya kini sudah diabaikan karena perkembangan ilmu pengetahuan dan teknologi (IPTEK), hal-hal tersebut diantaranya akibat dari kemudahan yang ditimbulkan oleh perkembangan teknologi kini manusia menjadi makhluk yang manja, hidup dengan ketergantungan pada teknologi, tidak mau lagi bekerja keras dalam menyelesaikan masalah-masalah dalam kehidupannya, sehingga ketika suatu keadaan mengharuskannya untuk tidak menggunakan teknologi, manusia seperti orang yang kehilangan arah dan tidak tahu harus berbuat apa. Hal inilah yang membuat manusia dapat terjebak pada pola hidup hanya untuk mengejar kenikamatan indriawi semata (http//puspadevianti.wordpress.com/2011/ 03/15/IPTEK-dalam-pandangan-hindu)

Agama memberi tuntunan agar manusia bisa memanfaatkan hasil penemuan IPTEK untuk kesejahteraan bersama. Dalam Hindu ilmu pengetahuan adalah suatu hal yang sangat diagungkan sebagai suatu anugerah Ida Sang Hyang Widhi Wasa yang didasari dharma, sehingga ketika seseorang memanfaatkan pengetahuan itu diharapkan selalu mengingat Ida Sang Hyang Widhi Wasa sebagai suatu bentuk pengalaman dari berkarma berdasarkan dharma dan kemudahan serta kenikmatan yang dapat diberikan oleh hasil pengembangan IPTEK itu tentunya patut disyukuri sebagai anugerah Tuhan. Dengan pengembangan IPTEK yang tepat dan akurat, berbagai hal dapat dilakukan dengan cepat praktis dan dapat memberi kemudahan dalam menjalankan kehidupan ini tetapi tetap berdasarkan dharma sehingga keseimbangan antara hal-hal tersebut dapat tercapai sekaligus tujuan hidup manusia untuk kebebasan di dunia dan moksa dengan berdasarkan dharma.

Salah satu hasil dari pengembangan IPTEK yaitu gadget. Akhir-akhir ini konsumsi gadget manejadi trend di masyarakat, bahkan dijadikan sebagai gaya hidup. Kementrian Komunikasi dan 
Informatika mencatat jumlah gadget di Indonesia sebanyak 240 juta unit, sedangkan jumlah penduduk Indonesia kurang lebih sebanyak 230 juta jiwa. Data ini menunjukan jumlah gadget lebih banyak dibandingkan jumlah penduduk Indonesia, hal ini memberikan gambaran bahwa satu oang memiliki dua gadget atau lebih. Tidak heran jika Indonesia masuk lima besar sebagai negara dengan pengguna gadget terbesar di dunia, karena masyarakat Indonesia per individu bisa memiliki dua atau bahkan lebih gadget dari berbagai merk dan tipe. Banyak alasan konsumen yang akhirnya menjadikan gadget sebagai gaya hidup, disamping karena mendapatkan prestise tinggi, gadget juga memberikan kemudahan dalam melakukan aktivitas sehari-hari.

Dengan hadirnya gadget, dunia menjadi transparan dan terasa seperti selembar daun kelor. Hubungan antarmanusia menjadi sangat mudah dan dekat, jarak waktu seakan tidak terasa dan seakan pula tanpa batas. Dengan hadirnya gadget pula, memberi peluang dan mendorong seseorang untuk melakukan tindakan-tindakan kejahatan. Walaupun sudah diberikan tuntunan dan masyarakat telah menciptakan hukum positif, penyalahgunaan teknologi masih selalu terjadi. Kejahatan dengan media komunikasi elektronik, seperti telepon seluler dan internet juga terjadi. Mulai bergosip, melecehkan orang lain, memfitnah, melakukan pembajakan, dan aksi terorisme yang dapat membuat masyarakat ketakutan. Berdasarkan latar belakang yang telah dipaparkan, permasalahan yang diangkat yaitu Implikasi Gadget terhadap masyarakat Hindu di Bali.

\section{PEMBAHASAN}

\subsection{Sejarah Gadget}

Menurut Wikipedia, gadget adalah sebuah istilah yang berasal dari bahasa Inggris, yang artinya perangkat elektronik kecil yang memiliki fungsi khusus. Dalam bahasa Indonesia, gadget disebut sebagai "acang". Salah satu hal yang membedakan gadget dengan perangkat elektronik lainnya adalah unsur kebaruan. Artinya, dari hari ke hari gadget selalu muncul dengan menyajikan teknologi terbaru yang membuat hidup manusia menjadi lebih praktis (http://en.wikipedia.org/wiki/Gadget).

Beberapa sumber lain mengatakan konon gadget berasal dari lelucon di abad 19. Istilah ini digunakan sebagai istilah pengganti untuk menyebut sebuah benda yang digunakan oleh seseorang dengan daya ingat rendah. Bukti anekdot penggunaan kata gadget ada di Kamus Inggris Oxford yaitu gadget sebagai nama tempat untuk menyimpan item teknis yang mana orang tidak dapat mengingat nama sebenarnya, hal ini berlangsung sejak tahun 1850-an. Contoh, pada buku Robert Brown, Spunyarn and Spindrift pada tahun 1886 menyebutkan seorang pelaut pulang dengan membawa clipper the Cina yang pertama kali dibuat dan digunakan lalu menyebutnya gadget. Secara etimologi kata gadget ini juga berarti sengketa. Konon asal usul kata gadget tercipta ketika tiga orang sedang melakukan pembangunan besar, yakni Patung Liberty di Amerika pada 1886. Tiga orang itu berasal dari Perancis bernama Gaget, Gauthier, dan Cie. Mereka bersengketa tentang miniature patung. (http://www.anneahira.com/gadget.htm).

Sementara itu, Michael Quinion, penulis Inggris penyumbamg tulisan dalam edisi kedua kata baru untuk kamus Oxford menulis asal usul istilah gadget. Menurutnya gadget identik dengan beberapa alat mekanis kecil, terkadang bentuknya tidak jelas, tapi alat ini pasti cerdik dan baru (Error! Hyperlink reference not valid.). Pendapat lain yang lebih masuk akal, istilah gadget berasal dari bahasa Perancis gchette yang dalam bahasa Indonesia berarti mencetuskan atau melahirkan sebuah gagasan baru. Hingga 1956, istilah gadget ini terus diperbincangkan. Sebuah esai yang ditulis oleh seorang kritikus arsitektur bernama Reyner Banham berjudul "The Great Gizno", mendifinisikan gadget sebagai benda dengan karakteristik unik, memiliki unit dengan kinerja tinggi dan berhubungan dengan ukuran serta biaya. Fungsi gadget adalah untuk mengubah sesuatu menjadi hal yang dibutuhkan manusia.

Dalam industri software, gadget mengacu pada program computer yang menyediakan layanan tanpa memerlukan sebuah aplikasi independen yang akan diluncurkan secara terpisah, melainkan berjalan di lingkungan yang mengelola beberapa gadget. Berdasarkan asal usul itu, maka tidak mengherankan bila handphone, laptop, tablet, dikatagorikan sebagai gadget. Berdasarkan fungsinya, tiga alat itu kini paling akrab, dan paling dibutuhkan oleh manusia dalam menjalani aktifitasnya sehari-hari. Contohcontoh dari gadget diantaranya telepon pintar (smartphone) seperti iphone dan blackberry, serta netbook (perpaduan antara computer portable seperti notebook dan internet)

\subsection{Pandangan Agama Hindu terhadap Perkembangan IPTEK}

Focus tugas ini yaitu melihat implikasi gadget pada masyarakat Hindu di Bali, bedasarkan fokus tersebut, maka diuaraikan terlebih dulu mengenai pandangan Agama Hindu terhadap kemajuan teknologi.

Dalam Hindu, ilmu pengetahuan adalah suatu hal yang sangat diagungkan sebagai suatu anugrah Ida Sang Hyang Widhi Wasa yang didasari dharma, sehingga katika seseorang memanfaatkan pengetahuan itu diharapkan selalu mengingat $I d a$ Sang Hyang Widhi Wasa sebagai suatu bentuk 
pengamalan dari berkarma berdasarkan dharma, dan kemudahan serta kenikmatan yang dapat diberikan oleh hasil pengembangan IPTEK itu tentunya patut disyukuri sebagai anugerah Ida Sang Hyang Widhi Wasa.

Dengan pengembangan IPTEK yang tepat dan akurat, berbagai hal dapat dilakukan dengan cepat praktis dan dapat memberikan kemudahan dalam menjalankan kehidupan ini, tetapi berdasarkan dharma, sehingga keseimbangan antara hal-hal tersebut dapat tercapai sekaligus tujuan hidup manusia untuk kebebasan di dunia dan moksa dengan berdasarkan dharma.

Dengan demikian adapat dikatakan bahwa dalam Hindu IPTEK adalah suatu hal yang memang merupakan suatu hal yang sangat penting. Karena Hindu mengagungkan ilmu pengetahuan sebagai suatu anugerah Tuhan untuk dapat didayagunakan dengan baik oleh manusia sehingga dapat mempermudah manusia dalam kehidupannya, tetapi kembali lagi kepada azas tunggal yang tidak dapat diabaikan, bahwa setiap hal harus dilakukan berdasarkan dharma, sehingga keseimbangan hidup dapat dicapai untuk menuju pada tercapainya tujuan hidup dalam agama Hindu yaitu Mokshartam Jagadhita Ya Ca iti Dharma (http:// puspadevianti.wordpress.com/2011/03/15/iptekdalam-pandangan-hindu).

Tujuan agama Hindu adalah Moksa dan Jagat Hita yaitu kesejahteraan sekala niskala, maka dalam mengejar kesejahteraan sekala niskala ini, mau tidak mau dihadapkan pada, karena mengikuti perekembangan dari zaman globalisai ini. Agama Hindu akan menerima perkembangan teknologi secara selektif, sepanjang tidak bertentangan dengan nilai-nilai agama Hindu. Dalam Agama Hindu teknologi itu hanya sebagai sarana penopang/ penunjang untuk mencapai hakekat daripada tujuan hidup beragama di dalam pelaksanaan upacara/ upakara agama. Di dalam kehidupan sebagai manusia beragama, teknologi berpengaruh di dalam mencapai kesejahteraan hidup dan kehidupan. Ajaran dari agama Hindu yang digunakan sebagai tolak ukur dalam menerima/menolak perkembangan teknologi itu, yaitu :

\section{Konsep Tri Semaya}

Konsep Tri Semaya yakni persepsi orang Hindu Bali terhadap waktu. Menurut orang Hindu Bali konsep Tri Semaya dibagi menjadi tiga yaitu penyesuaian dengan masa lampau (athita), penyesuaian dengan masa yang akan datang (anaghata) dan penyesuaian dengan masa sekarang (warthamana). Tri Semaya merupakan suatu rangkaian waktu yang tidak dapat dipisahkan satu dengan lainnya. Kehidupan manusia pada saat ini ditentukan oleh hasil perbuatan masa lalu dan perbuatan saat ini juga menentukan kehidupan di masa yang akan datang.

Kemajuan IPTEK memiliki implikasi yang sangat penting sekali dalam mempercepat, memperluas jangkauan penyebaran ajaran Weda yang merupakan kitab suci umat Hindu dan memuat pengetahuanpengetahuan Agama Hindu yang berasal dari masa lalu ke masa sekarang dan mendatang, dan konsekuensinya akan sekaligus mendobrak ajaran ajewera. Ajewera yang merupakan peringatan kepada semua orang untuk selalu hati-hati dalam mempelajari Weda. Ajewera berkaitan berbagai hal antara lain, Away sira pwang anglem druwya (tidak boleh tidak iklas); Arwya wak purusa (tidak boleh berkata kotor); Away sira angawu-ngawu (tidak boleh mengotori); Away angurang-ngurangi (tidak boleh mengurangi); Ujar menak pwa sira warahan (berkatalah yang baik mesti dalam ucapan). Semua itu mengandung maksud bahwa Weda mengandung pengetahuan rohani yang sangat rahasia dank arena itu perlu kehati-hatian dalam mempelajarinya dan menambahkan dengan komentar ajewer.

Prinsip kehati-hatian dalam memepelajasi Weda sudah disyaratkan oleh Bhagawa Wyasa di dalam Bhagawad Gita sebagai berikut,

"pengetahuan ini jangan pernah dijelaskan kepada orang yang tidak melakukan tapasya, tidak setia, tidak menekuni cinta bhakti atau yang iri kepadaKu" (BG 18.67)

"Siapa pun yang menjelaskan rahasia paling utama ini, akan mencapai bhakti yang murni dan akhirnya akan kembali kepada-Ku. Tidak ada orang di dunia ini yang lebih kucintai daripada dia" (BG.18.68-69)

Jadi demikian cara Weda diajarkan, bahwa siapapun yang bersedia menjadi dharmaduta Weda, itulah jaminannya. Namun harus memiliki kualifikasi yang sesuai terlebih dulu sehingga umat yang diajarkan akan menjadi umat-umat yang suci lahir batin dan bukan hanya sekedar menjadi anggota atau pengikut. Selain itu juga bukan sekadar menghafal semua sloka yang akhirnya berpikir bahwa dirinyalah yang paling berpengetahuan dan sukses. Ketika seseorang ingin mempelajari sebuah kitab suci berhati-hatilah senantiasa agar sikap perilaku mencerminkan sikap dan tingkah laku dari orang0orang suci yang dimuliakan (http:// www.balipost.co.id/balipostcetak/2003/3/19/s1.htm)

Konsep pendakian kesempurnaan Weda harus melalui sistem pewartaan Itihasa dan Purana, seperti dinyatakan dalam kitab Vayu Purana I.20 yang berbahasa sansekerta :Hendaknya Weda ditawarkan melalui Itihasa dan Puarana. Weda takut kalau orang bodoh membacanya. Weda berpikir bahwa orang 
bodoh itu akan melawan ajaran Weda. Sejalan dengan sloka Vayu Purana itu adalah Sarasamuscaya 39 dalam penjelasan bahasa Jawa Kunonya persis seperti isi Vayu Purana tersebut. Ini artinya artinya masyarakat yang tidak memiliki kemampuan atau kesempatan mendalami mantrammantram Weda Sruti dan sloka-sloka Weda Smrti dengan memahami isi Itihasa dan Purana sudah berarti mendalami isi Weda.

Mendalami isi Weda bukan untuk dihafal. Yang paling utama adalah pemahaman akan isi Weda itu dapat menimbulkan perubahan diri menuju perubahan diri yang semakin dekat dengan Tuhan ( Dewa Abhimana), semakin dekat dengan kebenaran (Dharma Abhimana) dan semakin dekat dengan pengabdian pada tanah kelahiran (Desa Abhimana). Melalui Itihasa dan Purana nilai-nilai Weda yang universal itu ditanamkan ke dalam sanubari umat. Dengan demikian nilai-nilai Weda tersebut menjadi bagian yang integral ke dalam diri setiap umat. Inilah yang lebih penting daripada menghapalkan syairsyair suci Weda (http://balipost.co.id/BALIPOST CETAK/2005/4/19/02.htm).

\section{Konsep Tri Pramana}

Konsep Tri Pramana mempunyai arti tiga cara umat Hindu meyakini adanya Ida Sang Hyang Widhi Wasa. Cara-cara tersebut adalah Pratyaksa Pramana (berdasarkan penglihatan langsung), Anumana Pramana (berdasarkan kesimpulan yang logis) dan Agama Pramana (berdasarkan kebenaran yang sesuai dengan ajaran kitab suci agama Hindu).

\section{Rasa, Utsaha, dan Lokika (akal)}

Tri Semaya, Tri Pramana, Rasa, Utsaha dan Lokika, semua hal itu harus disesuaikan dengan Desa (penyesuaian dengan tempat), Kala (penyesuaian dengan waktu) dan Patra (penyesuaian dengan keadaan) daerah setempat karena di Bali mempunyai desa, kala, patra yang berbeda-beda. Maka dari itulah perkembangan IPTEK harus disesuaikan dengan desa, kala, patra yang juga didukung dengan nilai-nilai dari ajaran agama. Jadi, gadget tetap saja memiliki keterbatasan dalam hal-hal yang bersifat khusus desa, kala, patra.

\subsection{Implikasi Gadget terhadap masyarakat Hindu di Bali}

Berikut diuraiakn Implikasi Gadget terhadap masyarakat Hindu di Bali berdasarkan teori tujuh unsur kebudayaan oleh Koentjaraningrat:

a. Peralatan dan Perlengakapan Hidup Manusia

Pergeseran masyarakat Hindu tradisional menuju masyarakat modern membawa dampak positif yang sangat signifikan yaitu masyarakat yang dulunya hidup tradisional, kini dapat beraktivitas jauh lebih mudah. Contoh: pada masyarakat tradisional untuk menjalin komunikasi dengan orang lain yang berada di suatu tempat yang jauh biasanya menggunakan tulisan tangan dalam bentuk surat, sekarang sudah bisa melalui gadget dengan fasilitas telepon, Short Messages Sevice (SMS) dan electronic mail (e-mail). Komunikasi dalam masyarakat Hindu di Bali menjadi cepat dan mudah dilaksanakan dengan hadirnya gadget, tanpa perlu membeli kertas, tinta, amplop dan perangko, serta tak perlu jauh-jauh ke kantor pos. Seseorang dengan mudahnya berkomunikasi atau melakukan percakapan melalui gadget, sehingga dapat menambah keakraban serta mempercepat persatuan bagi para umat seagama maupun berbeda agama, karena intensitas kemunikasi menjadi semakin murah, mudah, praktis, dan cepat, serta tidak terbatas ruang dan waktu.

Dampak positif lainnya yaitu dengan berkembangnya gadget pada masyarakat Hindu di Bali komunikasi tidak hanya dilakukan dengan alat komunikasi tradisional masyarakat Hindu Bali yaitu Kulkul, tetapi juga dilakukan dengan bantuan gadget. Kulkul yang terdapat di banjar atau yang biasa disebut kulkul banjar, masyarakat Hindu Bali memiliki spirit kebersamaan yang tinggi, karena setiap mendengar bunyi kulkul ditabuh, warga akan berbondong-bondong datang ke banjar untuk melakukan aktivitas gotong-royong, menandakan adanya warga yang meninggal dunia (kematian), menandakan adanya marabahaya, misalnya: banjir, kebakaran, pembunuhan, perampokan. Dengan hadirnya gadget, komunikasi yang dilakukan dapat sampai walaupun warga banjar berada di tempat atau lokasi yang jauh yang tidak tejangkau oleh suara kulkul.

Di samping dampak positif, terdapat juga dampak negatif dari hadirnya gadget. Dapat dilihat saat ini penggunaan kulkul pada masyarakat Hindu Bali sudah tidak seefektif dulu bahkan di beberapa banjar terutama di daerah perkotaan seperti Denpasar dan sekitarnya, kulkul sudah tidak digunakan lagi sebagai alat komunikasi. Selain itu dampak negatif pada hilangnya tradisi mengirim kartu ucapan yang sudah turun-temurun, serta kerapkali ucapan yang dikirim melalui gadget diambil atau di copy dari ucapan atau kata-kata milik orang lain yang telah terlebih dahulu mengirimkan ucapan. Bahkan tak jarang pula ucapan yang dikirim cukup ditulis hanya satu, kemudian dalam satu klik, semua orang yang 
masuk daftar penerima akan menerima ucapan yang sama. Hal ini tentunya berakibat ucapan yang dikirim terasa kurang sopan dan kurang berkesan.

b. Mata Pencaharian Hidup dan Sistem Ekonomi Dampak positif gadget dilihat dari mata pencaharian dan sistem ekonomi yaitu cukup banyak masyarakat Hindu di Bali yang bekerja atau menjadi pemilik perusahaan atau toko-toko penjual gadget, penjual kelengkapan gadget seperti pulsa, accessories gadget maupun pelayanan jasa perbaikan gadget. Dengan kata lain, hadirnya gadget membawa dampak positif bagi masyarakat Hindu di Bali yaitu dapat mengurangi pengangguran dan meningkatkan taraf hidup.

Gadget sebagai alat komunikasi juga berdampak positif yaitu sangat membantu masyarakat Hindu di Bali dalam bekerja. Bagi pengusaha gadget bisa digunakan sebagai alat kontrol dalam berbisnis misalnya dalam menjalin hubungan dengan karyawan atau rekan bisnis. Bagi masyarakat Hindu di Bali yang berprofesi sebagai petani maupun pedagang hadirnya gadget sangat membantu disaat petani maupun pedagang ingin menjual hasil panen atau barang dagangannya. Petani maupun pedagang menjalin hubungan dengan pembeli. Kemampuan pelayanan internet yang dimiliki gadget juga dapat mempermudah dalam sistem jual beli diantara penjual dan pembeli ditambah lagi transaksi yang kini dapat dilakukan secara mobile dengan bantuan gadget.

Gadget menawarkan fitur browsing dengan tampilan yang cukup untuk melihat barang dan melakukan transaksi. Sebagai contoh, begitu halnya dengan masyarakat Hindu Bali yang menjual peralatan maupun perlengkapan sembahyang melalui situs online seperti menjual kebaya, kain, udeng. Berbagai alternative promosi yang praktis dan murah saat menjual juga dapat dilakukan melalui gadget. Gadget memberikan kemudahan memilih promosi alternatif untuk mensosialisasikan bisnis pada masyarakat baik melalui iklan baru, SMS atau e-mail maupun melalui media sosial seperti facebook dan twitter.

Dampak negatif hadirnya gadget yaitu seringkali masyarakat tertipu oleh pedagangpedagang nakal yang menawarkan atau mempromosikan barang dagangannya memiliki gadget. Penipuan yang terjadi misalnya ketika uang sudah ditransfer oleh pihak pembeli, barang tidak dikirim oleh pihak penjual atau kondisi barang tidak sesuai dengan yang ada di foto atau rincian detail barang.

c. Sistem Kemasyarakatan

Dampak positif hadirnya gadget menyebabkan dunia menjadi transparan, terasa seperti sehelai daun kelor yang segalanya seakan mudah untuk dijangkau dalam genggaman tangan, karena hubungan menjadi sangat mudah dan dekat, jarak dan waktu seakan tidak terasa dan seakan pula tanpa batas. Di sisi lain kehadiran gadget juga membawa dampak negatif yaitu menciptakan kesenjangan sosial dalam masyarakat Hindu di Bali. Kesenjangan sosial yang tercipta seperti jarak antara si kaya dan si miskin dan hal ini bisa merusak nilai-nilai dan juga akan memicu prasangka sosial maupun persaingan dalam kehidupan. Mempunyai penghasilan besar mungkin bisa menjadikan alasan seseorang memiliki lebih dari satu gadget. Ketika konsumsi gadget bukan lagi sebuah kebutuhan tetapi menjadi sebuah keinginan, maka akan mudah berganti gadget ketika harga gadget turun, atau ketika ada gadget tipe baru yang dikeluarkan. Inilah yang menyebabkan gadget menjadi alat sebagai gaya hidup yang dipandang di masyarakat sebagai ukuran kekayaan.

Hadirnya gadget juga menyebabkan masyarakat Hindu di Bali menjadi individualistis. Masyarakat merasa sangat dimudahkan dengan gadget dan membuat merasa tidak lagi membutuhkan orang lain dalam aktivitasnya. Kadang-kadang masyarakat lupa akan dirinya sebagai makhluk sosial dan cenderung untuk hidup sendiri-sendiri tanpa memperhatikan orang lain, rasa gotong royong, ramah tamah dan sopan santun mulai memudar. Nilai-nilai yang telah dijunjung sesuai budaya leluhur masyarakat Bali mulai ditinggalkan. Akibat dari memudarnya nilai-nilai budaya lokal akan menimbulkan sikap individualistis.

Penggunaan gadget dengan fasilitas internet juga menimbulkan efek negatif yang merugikan masyarakat sendiri. Tak jarang terjadi perselisihan akibat kesalahpahaman maksud dan tujuan ataupun karena salah memajang status atau memberikan komentar suatu status facebook dan jejaring sosial lainnya, yang akhirnya justru menambah renggangnya hubungan di masyarakat. Konflik yang terjadi akibat kesalahan di dunia maya memamng sangat mungkin terjadi, karena kata-kata yang diucapkan lewat facebook mungkin sering menimbulkan salah paham. Adakalanya 
pertengkaran itu dilanjutkan di dunia nyata yang berakhir dengan perkelahian. Bahkan tidak sedikit kasus perselingkuhan dalam rumah tangga terjadi lewat akun facebook. Awalnya mungkin karena iseng-iseng mengisi waktu, mencari teman curhat, terus menjadi keasyikan dan akhirnya berlanjut pada tahap yang serius cenderung negatif. Kalau sudah demikian, maka jangan heran jika berakibat pada pertengakaran antar pasangan dan lebih parah lagi bisa memicu perceraian.

d. Bahasa (Lisan, Tulisan)

Salam dalam masyarakat Hindu Bali atau biasa disebut panganjali adalah $\mathrm{Om}$ Swastyastu yang artinya yaitu Semoga Selamat. Akhir-akhir ini dengan hadirnya gadget, maka salam itu pun mengalami perkembangan dalam penulisan yang disingkat dalam mengirim SMS seperti diketik kata OSA, yang seakan singkatan dari Om Swastyastu, OSSSO yang diartikan sebagai kepanjangan dari Om Shanti, Shanti, Shanti, Om. Namun di dalam surat menyurat resmi antar instansi Hindu tetap saja penulisan salam pembuka dan penutup dengan kata yang lengkap, yaitu Om Swastyastu dan Om Shanti, Shanti, Shanti, Om yang artinya semoga selamat dan semoga damai di hati damai di bumi damai selalu.

\section{e. Sistem Pengetahuan}

Gadget dipandang sebagai jendela yang memungkinkan khalayak melihat sesuatu yang sedang terjadi di luar sana atau merupakan sarana belajar untuk mengetahui berbagai peristiwa. Dengan kata lain gadget membawa dampak positif yaitu bisa membentuk sumber daya manusia yang intensif karena umat secara tidak langsung memperoleh pengetahuan agama melalui penggunaan gadget. Penyebaran ajaran-ajaran agama Hindu juga bisa dilakukan dengan mudah melalui gadget. Tetapi tetap saja memiliki keterbatasan dibanding dengan sistem pendidikan langsung di pasraman, karena sangat terkait dengan pendalaman psikologi peserta didik oleh para guru spiritual.

Dampak negatif gadget dari segi pengetahuan yaitu pengetahuan-pengetahuan yang diperoleh memalui gadget tidak bisa dipastikan kebenarannya, misalnya penafsiranpenafisiran agama Hindu yang tidak sesuai (salah penafsiran). Walau sangat canggih, maka tetap saja teknologi informasi memiliki keterbatasan dalam menyampaikan ajaran agama, terutama dalam hal penglihatan langsung dan penarikan kesimpulan logis yang bisa menyesatkan tanpa bimbingan seorang guru yang berkualifikasi di bidang spiritual Weda. Di dalam kitab Sarassamuccaya, juga dalam Visnu Purana, disebutkan bahwa Weda tidak boleh dipelajari oleh orang awam. Untuk dapat dibolehkan mempelajari Weda, salah satu syaratnya harus mempelajari Itihasa dan Purana, Ramayana dan Mahabarata tergolong ke dalam Itihasa (http:/edukasi. kompasiana. com/2013/08/23/salah-kaprah-tentangmahabarata-585925.html).

Dalam kaitan ajaran agama Hindu keberadaan IPTEK memiliki implikasi yang sangat penting sekali dalam mempercepat, memperluas jangkauan penyebaran ajaran Weda yang berasal dari masa lalu ke masa sekarang dan mendatang, dan konsenkuensinya akan sekaligus mendobrak ajaran ajewera. Masalahnya apabila ajaran ajewera dilabrak, maka kebebasan ini bisa menjadi boomerang bagi kebenaran yang sepatutnya ingin disampaikan oleh kitab suci, diakibatkan oleh keterbatasan dan kebodohan dalam menafsiran oleh orang-orang yang belum memiliki kualifikasi sebagai duta dharma.

\section{f. Religi (Sistem Kepercayaan)}

Dampak positif hadirnya gadget yaitu dapat mebantu masyarakat Hindu Bali dalam beribadah karena gadget memiliki banyak aplikasi Agama Hindu misalnya aplikasi kalender berguna untuk memberikan informasi mengenai jadwal berbagai upacara keagamaan di beberapa pura besar di Bali, terutama Pura Besakih. Pustaka Hindu memuat kumpulan doadoa keseharian, juga kitab suci Bhagavad Gita dan Sarasamuscaya. Kehadiran gadget dalam masyarakat Hindu Bali mampu mempercepat dan memperluas penyebaran pengetahuan umum agama Hindu, untuk memenuhi kebutuhan umat yang kini semakin haus akan ajaran Hindu. Seperti kata pepatah mengatakan "jika tak kenal, maka tak sayang" dan "semakin kenal, maka semakin sayang”. Dengan bantuan gadget ini umat Hindu menjadi semakin kenal dan sayang akan ajaran agamanya sendiri, terbukti kebangkitan umat untuk bertirtha yatra setiap hari penting Hindu semakin meningkat terutama di kalangan kawula mudanya. Hal ini sejalan dengan konsep Tri Pramana yaitu agar para umat yang beragama Hindu mengaplikasikan nilai-nilai agamanya pada teknologi meningkatkan atau memperdalam keimanan kepada Tuhan.

Penggunaan gadget bila digunakan untuk memperdalam pengetahuan dan keimanan itu baik. Tetapi sebaliknya dan ini sebuah 
kenyataan bahwa gadget membawa dampak negatif jika digunakan untuk mengakses video porno atau yang bertentangan dengan normanorma agama Hindu . Selain itu apresiasi terhadap nilai budaya lokalpun pudar serta nilai keagamaan akan mengalami kemunduran. Dapat dilihat pergeseran nilai yaitu beralih ke budaya barat dan budaya lainnya. Seringkali ditemui juga bahwa seseorang melupakan atau menunda kegiatan ibadah karena terlanjur asyik dengan fitur gadget yang menarik seperti game, akses, social media. Melalui gadget dengan mudahnya seseorang terangsang pola hidup konsumerisme yang berlebihan hingga terjerumus ke pola hidup hedonism, yakni hidup dengan memikirkan kepuasan dan kenikmatan semata-mata.

g. Kesenian

Musik Hindu atau yang dikenal dengan istilah kidung jarang diminati oleh masyarakat Hindu Bali terutama kalangan remaja. Seiring hadirnya gadget, masyarakat Hindu Bali terutama remaja dapat dengan mudah mengakses maupun menyebar Kidung Bali. Tak jarang pula yang bahkan menjadikan Kidung Bali sebagai nada dering atau ringtone pada gadget miliknya. Dengan kata lain haidirnya gadget menyebabkan Kidung Bali menjadi lebih dikenal dan mendorong seniman-seniman Hindu Bali untuk semakin berkarya.

\section{PENUTUP}

Pada era globalisasi telah terjadi perubaahanperubahan yang berlangsung sangat cepat. Dunia menjadi transparan, terasa sempit, hubungan menjadi sangat mudah dan dekat. Jarak waktu seakan tidak terasa dan seakan pula tanpa batas dengan hadirnya gadget. Agama Hindu tidak pernah melarang umatnya untuk memenuhi kebutuhan/ keinginan hidupnya, namun ada batasan-batasan yang harus diperhatikan.

Jika ditimbang-timbang, dampak negatif yang timbul akibat gadget sesungguhnya bersumber dari penggunanya (user) itu sendiri. Pengguna, dalam ini manusia tentunya merupakan kunci utama atau pengendali agar jangan sampai terjadi hal-hal yang tidak diinginkan. Menurut ajaran Hindu, manusia dibekali dengan Tri Pramana yaitu Bayu (Tenaga), sabda (Perkataan), dan Idep (Pikiran). Inilah yang membedakan manusia dengan makhluk hidup lainnya yaitu hewan dan tumbuhan. Hewan memiliki bayu dan sabda, sehingga dapat beregerak dan bersuara. Sedangkan tumbuhan hanya memiliki bayu/tenaga untuk tumbuh dan berkembangbiak.

Dengan segala keunggulan yang dimiliki itulah semestinya manusia dapat benar-benar menjadi makhluk yang utama. Manusia seharusnya dapat menggunakan akal budhi dan pikirannya untuk bisa melakukan apa yang seharusnya dilakukan dengan penuh kesadaran dan tanggung jawab. Selain ittu, manusia juga memiliki Wiweka yaitu kemampuan untuk membedakan serta meilah-milah baik dan buruk, benar dan salah dan sebagainya. Sesungguhnya jika wiweka manusia tersebut benarbenar difungsikan atau digunakan dengan baik, maka hal-hal negatif di dunia maya maupun di dunia nyata tentu akan dapat dihindarkan.

\section{DAFTAR PUSTAKA}

Kontjaraningrat.200. Pengantar Ilmu Antropologi. Jakarta: Radar Jaya Offset.

Sunarso, dkk.2006. Pendidikan Kewargane-garaan. Yogyakarta. UNY-Press.

Studi Internet :

Adnyani, Ni Made.2012. Rsi Vyasa Sang Pangeran Penemu Teknologi Vidio Call. (serial online). Available from; URL: http:/tamandharma. blogspot.com/2012/08/rsi-vyasa-sang-penemu-teknologi-vidio.html. diakses 30 september 2014.

Devianti, puspa.2011. IPTEK Dalam Pandangan Hindu. (serial online). Available From. URL: http://puspadevanti.wordpress.com/2011/03/ 15/IPTEK-dalam-pandangan-hindu/.Diakses 30 September 2014.

Gobyah.2003. Intisari Tradisi Hindu adalah Weda. (serial online).Available from: URL:http:// www.balipost.co.id/BALI POSTCETAK/ 2003/3/19bd4.htm. Diakses 30 September $\underline{2014}$.

Indri. 2009. Pemanfaatan Teknologi Informasi dan Komunikasi Dalam Agama Hindu. (serial online).Available From: URL: http:// indrimyutz. wordpress.com./2009/10/30/ pemanfaatan-teknologi-si-dankomunikasidalam-agama-hindu/. Diakses 30 September 2014

Mupu, Merta.2013. Salah Kaprah Tentang Mahabharata. (serial online). Available from:URL; http://edukasi.kompasiana. com/ 2013/08/23/salah-kaprah-tentangmahabharata-585925.html. Diakses 30 September 2014.

Wikipedia.2014.Gadget. (serial online). Available from: URL:http:// en.wikipiedia.org/wiki/ Gadget.Diakses 30 September 2014 